\title{
FALACIA NATURALISTA Y LEY DE HUME: SU SIGNIFICADO EN DERECHO PENAL
}

\author{
NATURALISTIC FALLACY AND HUME'S LAW: ITS MEANING IN \\ CRIMINAL LAW
}

\section{Orlando Humberto De la Vega Martinis*}

\begin{abstract}
RESUMEN: El texto se esfuerza por aclarar el significado de la falacia naturalista y de la ley de Hume, apartándose de la comprensión tradicional de acuerdo con la cual no sería posible derivar el deber del ser, ni un juicio valorativo de uno descriptivo. Las reflexiones cierran analizando la capacidad de rendimiento de la falacia naturalista y la ley de Hume en derecho penal. En particular, mostrando cómo ellas son usadas como estrategia de encubrimiento del carácter radicalmente político de la legislación.
\end{abstract}

Palabras clave: Falacia naturalista, ley de Hume, silogismo práctico, democracia, derecho penal.

ABSTRACT: The text strives to clarify the meaning of the naturalistic fallacy and the Hume's law, departing from the traditional understanding according to which it would not be possible to derive an ought from an is, nor an evaluative judgment from a descriptive one. The reflections close analyzing the performance capacity of the naturalist fallacy and Hume's law in criminal law. In particular, showing how they are used as a strategy to cover up the radically political nature of legislation.

Key words: Naturalistic fallacy, Hume's law, practical syllogism, democracy, criminal law.

\section{PRESENTACIÓN}

En una temprana decisión la Corte Constitucional colombiana afirmó que del concepto estado social de derecho se deriva la siguiente comprensión del derecho: "pérdida de la importancia sacramental del texto legal entendido como emanación de la voluntad popular y mayor preocupación por la justicia material y por el logro de soluciones que con-

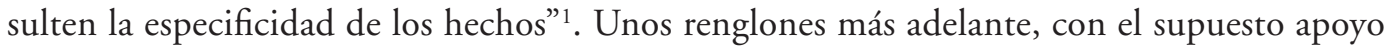
teórico de H.L.A. Hart, agregó: "Hoy, con la nueva Constitución, los derechos son aquello que los jueces dicen a través de las sentencias de tutela”2. El caso que ocupó la atención de la corte en aquella ocasión no era un caso de derecho penal, sino de administrativo. Un ejemplo en el que la Corte Constitucional colombiana aplica esa comprensión del derecho en derecho penal es su reciente declaratoria de inconstitucionalidad del delito de propaga-

* Dr. iur por la Universidad de Bonn, Alemania. Profesor Asistente del Departamento de Derecho Penal de la Pontificia Universidad Javeriana, Bogotá. Dirección postal: calle 40 № 6-23 Piso $7^{\circ}$ Edificio Gabriel Giraldo, S.J., Bogotá, Colombia. Dirección electrónica: odelavega@javeriana.edu.co.

1 Corte Constitucional. Sentencia T-406.

2 Corte Constitucional. Sentencia T-406. 
ción del virus de inmunodeficiencia humana. De acuerdo con la Corte, el legislador habría contribuido a la discriminación y estigmatización del portador del virus de inmunodeficiencia humana mediante la penalización de su propagación ${ }^{3}$. Unos renglones más adelante agrega: "a pesar de que en materia de derecho penal el Legislador cuenta con una amplia libertad de configuración normativa, en su labor debe aún respetar los principios constitucionales de proporcionalidad, razonabilidad e igualdad"4. Ese pesar que siente la Corte por la función del legislador resulta visible en su esfuerzo argumentativo por mostrar que la decisión del legislador fue irracional. En particular, despliega argumentos para probar cómo el texto legal no consulta la especificidad de supuestos hipotéticos planteados por la corte. Y la sala penal de la Corte Suprema de Justicia colombiana acompaña a la Corte Constitucional en este propósito de fomentar un rol subordinado de la ley. Por solo mencionar un ejemplo, en una ocasión se negó a aplicar una ley por considerar que el aumento de pena previsto en ella para el delito de extorsión quebrantaba el principio de proporcionalidad. Sin dicho principio, dijo la Corte, la práctica legislativa "devendría en arbitrariedad legislativa, por cuanto se admitiría la existencia de márgenes de castigo carentes de justificación, emanados de la simple voluntad del legislador"5.

La situación destacada en el párrafo anterior no es originaria ni exclusiva de Colombia. Se trata del reemplazo de la supremacía de la ley por la supremacía de la constitución. Para entender por qué un juez no debería sentirse primariamente vinculado a la ley sino a la constitución se suele enfatizar "la irracionalidad en la que los procedimientos de formación de voluntad política pueden desembocar" ${ }^{6}$. Ese fue, justamente, el libreto seguido por la Corte Constitucional en la decisión que declaró inexequible el delito de propagación del virus de inmunodeficiencia humana y por la sala penal de la Corte Suprema de Justicia en la decisión en la que se negó a aplicar la ley que aumentó, entre otras, la pena del delito de extorsión. Que la ley declarada inconstitucional y la inaplicada fueran emanación de la voluntad popular es secundario frente a la justicia material y la especificidad de los hechos. En este contexto Atria ha puesto de presente cómo la corriente de pensamiento denominada neo-constitucionalismo, exportada por "juristas italianos y filósofos alemanes”, pretende hacerle frente a la irracionalidad de la ley erigiendo al juez y a la ciencia del derecho en juez del legislador ${ }^{8}$. La razón principal por la cual esa respuesta neo-constitucionalista es errada es que ella "pone en riesgo la idea de autogobierno democrático (que constituye al menos el ideal regulativo que funda nuestras prácticas democráticas, de acuerdo al cual

\footnotetext{
3 Véase Corte Constitucional. Sentencia C-248, p. 2015.

4 Corte Constitucional. Sentencia C-248, p. 2024.

5 Corte Suprema de Justicia. Sentencia 33254. Resulta curioso, en todo caso, que la Corte Suprema de Justicia entienda desproporcionado un marco punitivo que va de 16 a 24 años, sin aducir razón alguna que hable a favor de la proporcionalidad del marco punitivo anterior a la ley inaplicada, que va de 12 a 16 años. La simple mención de la fórmula de Radbruch no contesta la pregunta de por qué solo el segundo marco punitivo sería derecho injusto.

6 Atria (2016) p. 67.

7 Atria (2016) p. 67.

8 Véase Atria (2016) p. 68. Y su afirmación, con arreglo a la cual Latinoamérica es el lugar donde mejor se ha recibido dicha corriente, se hace verdadera en Colombia; véase, aparte de las decisiones ya citadas, Corte Constitucional. Sentencia C-83.
} 
somos nosotros, el pueblo quienes nos auto-gobernamos) y la idea de gobierno conforme a

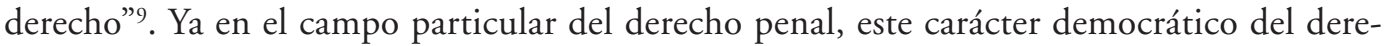
cho penal es visto con preocupación por profesores de derecho penal que creen que existe un derecho penal correcto con independencia de su origen democrático ${ }^{10}$. Sin embargo, como Mañalich recientemente demostró, la idea de parámetros pre-políticos de legitimación del derecho (Mañalich lo denomina principialismo, pero coincide con lo que Atria denomina neo-constitucionalismo) pretende ofrecer "una modelación no-política de un determinado espacio de disputa política ... siendo el caso que esa modelación resulta ser irreductiblemente política, lo cual quiere decir: políticamente controvertible"11.

Uno de los juristas italianos que ha exportado la idea, neo-constitucionalista o principialística, de parámetros pre-políticos de legitimación del derecho es Ferrajoli. De él me interesa el uso que hace de los términos ley de Hume y falacia naturalista, para mostrar cómo dichos conceptos, por sí mismos, no tienen la utilidad que el autor en comento les atribuye en derecho penal. La relevancia del ejercicio descansa en su capacidad de mostrar que ni la ley de Hume ni la falacia naturalista hacen operativa la idea, defendida por Ferrajoli, de que en un modelo de estado constitucional la ciencia jurídica puede imponer prohibiciones y obligaciones de contenido al legislador ${ }^{12}$. Se trata en últimas, como afirma Mañalich, de una estrategia de enmascaramiento del carácter políticamente controversial de los postulados presentados como axiomas ${ }^{13}$. Con una grave consecuencia: cultivar esa postura promueve la ausencia de controversia de cara a decisiones de política criminal. Por el contrario, una correcta interpretación de Hume favorecerá un sano ejercicio de discusión basado en razones. Y frente a este último punto valga desde ya una aclaración. En la sección III de este artículo me interesa interpretar correctamente a Hume porque Ferrajoli afirma descansar en Hume, aunque quizás haya buenas razones para abandonar la forma humeana de razonamiento práctico ${ }^{14}$. En las líneas que siguen pretendo, entonces, abordar la falacia naturalista (sección II) y la ley de Hume (sección III).

A modo de introducción a las secciones II y III valgan las siguientes reflexiones. ¿Es posible pasar de la proposición "la olla con agua lleva 10 minutos en el fuego" a la proposición "el agua debe estar hirviendo en este momento"? 15 , ¿es posible concluir que "A debe ser castigado" con la sola presencia de la afirmación "A mató a B"? o, en un supuesto más complejo, ¡es posible derivar de la proposición "A desea tomarse una cerveza" la proposi-

\footnotetext{
9 Atria (2016) p. 68, bastardillas en el original.

10 Así, por ejemplo, Silva Sánchez (2018) pp. 40-45.

11 Mañalich (2018) p. 62, bastardillas en el original.

12 Véase Ferrajoli (2001) p. 34. La idea general es que este "nuevo" modelo de estado constitucional reemplazaría al modelo de estado legalista. En ese mismo contexto Suárez llega a la misma conclusión que Ferrajoli: "Existen ... unos límites ontológicos que deben ser respetados por el jurista penalista. Tanto por el legislador en la formulación de la ley como por el científico del derecho penal en la construcción dogmático-jurídica, existen unas barreras que están dadas por el ser de las cosas"; véase SuÁreZ (2010) p. 43.

13 Véase Mañalich (2018) p. 62.

14 Véase Brandom (2000) pp. 79-96. El punto estriba en qué se quiere privilegiar, ¿̇la inferencia o la referencia, la expresión o la representación?. Para una correspondiente semántica inferencial véase Brandom (1994) pp. 67 ss.

15 Ejemplo tomado de Strawson (1952) p. 235.
} 
ción "A debe ir hasta la nevera a recoger la cerveza"? ${ }^{16}$ A primera vista es razonable pensar que solo la segunda pregunta es de interés para el jurista, mientras que las otras dos aparentan poseer un interés a lo sumo de carácter general. No obstante ello, la justificación que se dé a la respuesta de la segunda pregunta no es distinta de la justificación que se dé a las respuestas de las dos preguntas restantes, o por lo menos eso se afirmará en el presente artículo. En términos generales, y ese es el común denominador de las tres preguntas, en todas ellas se trata de la relación entre una proposición que es cierta y una proposición que debería ser cierta.

No obstante este punto en común, hay diferencias notables entre ellas. Así, la proposición "el agua debe estar hirviendo en este momento" es una proposición que debe ser cierta en un sentido no moral del término deber, de la misma forma en que a un aprendiz de ajedrez se le dice que no debe mover la torre en diagonal ${ }^{17}$. A su turno, y seguro ahí radica la importancia para el jurista, la proposición "A debe ser castigado" es una proposición que debe ser cierta en un sentido moral del término deber ${ }^{18}$. Finalmente, la proposición "A debe ir hasta la nevera a recoger la cerveza" es una proposición que debe ser cierta si se le asigna racionalidad a A. La tercera pregunta, por ello, presenta una característica estructural de la mente que en las dos primeras está tácitamente presupuesta, a saber, la referencia intencional frente al mundo ${ }^{19}$. En lo sucesivo, este importante aspecto será dejado de lado ${ }^{20}$.

Otra pregunta emparentada con las anteriores es la siguiente: ¿es posible, dada la proposición "X equivale a ayudar al prójimo", concluir en la proposición "X es bueno"? Salta a la vista que en esta pregunta no se trata, como en las tres primeras, de la relación entre una proposición que es cierta y una proposición que debería ser cierta, sino de dos proposiciones que son ciertas y cuya diferencia radica en las distintas características que acompañan sus respectivos contenidos proposicionales. Así, mientras que el contenido proposicional de la primera oración está acompañado por una característica descriptiva (ayudar al prójimo), el contenido proposicional de la segunda oración lo está por una característica valorativa (bueno). La incorporación del concepto básico axiológico de lo bueno seguro sirve de estímulo al jurista para ocuparse de esta cuarta pregunta. Una vez más, la justificación que se dé a su respuesta tampoco será distinta de la justificación que se dé de cara a las respuestas de las tres primeras preguntas formuladas arriba, o por lo menos eso se afirmará aquí21.

\footnotetext{
16 Ejemplo tomado de BeCKermann (2008) p. 16.

17 Véase Mackie (1977) p. 65. También podría decirse que deber en este contexto significa predicción, pero este cambio no haría ninguna diferencia, desde la perspectiva de Hume, con los usos de deber expuestos en los restantes ejemplos; al respecto véase Goodman (1983) p. 61. Otra cosa es entender que una predicción es la conclusión del reconocimiento de un compromiso cognitivo, mientras que deber es la conclusión del reconocimiento de un compromiso práctico; al respecto véase BRANDOM (2000) p 85.

18 Esta observación no conduce necesariamente a una relación de dependencia entre el derecho y la moral. Así, es perfectamente posible que ambos tengan ámbitos de validez independientes y que, no obstante ello, los razonamientos morales sean importantes para el derecho; al respecto véase Habermas (1992) pp. 135 y 139.

$19 \mathrm{Al}$ respecto véase BecKermann (2008) p. 13 ss.; Grundmann (2008) p. 24 ss.

$20 \mathrm{Al}$ respecto, el desarrollo de una muy interesante teoría del significado puede verse en DAVIDSON (2001a) pp. 125 ss.; el mismo (2001b) pp. 137 ss.; acerca de la voluntad racional véase Brandom (2000) pp. 93 ss.

${ }^{21}$ De otra parte, la proposición "X es bueno" también puede, bajo ciertas circunstancias que no son objeto de este trabajo, ser leída como "X es debido", pues una norma de conducta es, a la vez, norma axiológica de valo-
} 
¿Cómo han de ser contestadas estas cuatro preguntas? La prohibición lógica de deducir conclusiones prescriptivas (deber) de premisas descriptivas (ser) se denomina, desde la contribución de Hare ${ }^{22}$, ley de Hume. De conformidad con esta ley habría que contestar negativamente las tres primeras preguntas formuladas arriba. Por su parte, la definición de lo bueno a través de proposiciones descriptivas se conoce, desde la obra de G.E. Moore ${ }^{23}$, como falacia naturalista. De acuerdo con ella la pregunta cuatro debería contestarse también de forma negativa. Pero, ¿son satisfactorias las justificaciones para estas respuestas? $y$, en particular, ¿̇tienen algún rendimiento estas justificaciones en derecho penal?. Como muy bien lo anota Mackie ${ }^{24}$, en éste y en otros campos "la filosofía moral aparece como el pariente pobre de la ciencia jurídica”. No obstante esta apariencia, es mucho lo que el jurista tiene para aprender de su "pariente pobre" 25 . Así, objeto de la sección III del presente artículo es reivindicar el sentido y alcance de las palabras de Hume, en el sentido de negar que exista una ley de Hume con el contenido: "Está prohibido pasar de una premisa descriptiva a una conclusión prescriptiva”, como creen algunos juristas ${ }^{26}$ (y también algunos filósofos morales ${ }^{27}$ ), pues esta fórmula corresponde a una visión que trivializa las definiciones de descriptivo y prescriptivo. El desarrollo de este punto permitirá aproximar una respuesta al problema de la transición entre ser y deber. Por su parte, objeto de la sección II del presente trabajo es demostrar que la así denominada falacia naturalista corresponde a una visión que trivializa las definiciones de descriptivo y evaluativo. En este sentido puede hablarse de la falacia de la falacia naturalista ${ }^{28}$. El desarrollo de este punto permitirá delinear una definición del término bueno y, con ello, se aproximará una respuesta al argumento de la cuestión abierta tradicionalmente asociado a la falacia naturalista. Finalmente, lo anterior debe llevar, en la sección IV, a una revisión del significado de la ley de Hume y de la falacia naturalista en Ferrajoli.

Un punto que debe abordarse previo al análisis de la definición del término bueno y del tránsito entre ser y deber, y que vale para ambos, es el relativo a la distinción entre contenido y estatus, el cual, aplicado en ética permite hablar de juicios morales de primer nivel (contenido de la moral) y juicios morales de segundo nivel (estatus de la moral) ${ }^{29}$. Así, por ejemplo, afirmar que "X es bueno" o que "A debe ser castigado" son ambos juicios morales de primer nivel. Estos juicios afirman que un determinado curso de acción es bueno o malo o debido o indebido, o proveen de un principio general mediante el cual se pueden inferir

ración y norma deontológica de determinación. Al respecto véase KINDHÄUSER (1989) pp. 150 ss.; últimamente también MaÑALICH (2009) pp. 43 ss.

22 Hare (1954-1955) p. 303; el mismo (1952) p. 29.

23 MoOre (1903) p. 10.

24 Mackie (1977) p. 164.

25 En igual sentido Neumann (1991) pp. 248 ss.; el mismo (1994) pp. 81 ss.

26 Véase Ferrajoli (1995) pp. 220, 241, 323 ss., 359 y 921; véase también SuÁrez (2010) pp. 32 ss.

27 Compárese MacInTYRe (1959) p. 451, con ulteriores referencias.

28 La expresión es de SEARLE (1969) pp. 132 ss. No obstante, las razones que permiten aquí hablar de una falacia de la falacia naturalista son distintas de las expuestas por Searle. Una posición similar a la aquí defendida y contraria a Searle puede verse en FLEW (1964) pp. 25 ss.

$29 \mathrm{Al}$ respecto véase MACKIE (1977) p. 9. 
en detalle juicios de este tipo ${ }^{30}$. Por su parte, un juicio moral de segundo nivel dice "qué pasa cuando alguien hace un juicio de primer nivel, en particular si un juicio de este tipo expresa un descubrimiento o una decisión, o también puede referirse a cómo pensamos y razonamos sobre asuntos morales, o puede ofrecer una idea acerca de los significados de varios conceptos éticos" ${ }^{31}$. La importancia de esta distinción radica en lo que Austin llamó análisis ilocucionario, pues lo decisivo en él es "determinar en qué sentido se está usando la alocución: preguntando o respondiendo algo, dando alguna información o afirmando o previniendo, anunciando un veredicto o una intención, pronunciando una oración, haciendo un apunte o una remisión o una crítica, identificando algo o dando una descripción, u otros usos similares" 32 .

Esta distinción resulta crucial de cara al análisis que aquí nos ocupa, pues la relación entre una proposición descriptiva y una valorativa (por ejemplo, la definición del término bueno a partir de cualidades naturales) así como la relación entre una proposición descriptiva y una prescriptiva (por ejemplo, la definición de deber a partir del ser) son temas ambos que se ubican en el plano del estatus de la moral, esto es, en el plano de los juicios morales de segundo nivel. Por el contrario, la proposición "A debe ser castigado" o la proposición "X es bueno", traídas a cuento atrás, son juicios morales de primer nivel en la medida en que ellas informan que un curso de acción es debido y que un curso de acción es bueno, respectivamente. Ahora, de conformidad con la distinción entre contenido y estatus, no es objeto de este artículo razonar sobre estos contenidos, afirmando, por ejemplo, que hay razones utilitaristas para pensar que el asesino debe ser castigado o, una vez más a título de ejemplo, afirmando que hay razones deontológicas que hablan a favor de la ayuda al prójimo, por solo mencionar dos de las tesis más relevantes en el plano del contenido de la moral ${ }^{33}$. Lo que aquí interesa, entonces, es saber qué pasa cuando se afirma "A debe ser castigado" o cuando se afirma "X es bueno" y, en particular, averiguar si dichas proposiciones están asociadas a algún tipo de proposición con carácter descriptivo, y en caso que lo estén, de qué manera.

De esta forma, una teoría que legitime el tránsito de ser a deber proveerá la justificación para la respuesta a las tres primeras preguntas formuladas atrás, de la misma forma como una teoría que legitime el paso de una oración cuyo contenido proposicional está acompañado por una característica descriptiva a una oración cuyo contenido proposicional está acompañado por una característica valorativa proveerá la justificación para la respuesta a la pregunta cuatro. Es conveniente comenzar por este último punto, es decir, por el paso de una oración cuyo contenido proposicional está acompañado por una característica descriptiva a una oración cuyo contenido proposicional está acompañado por una característica valorativa, lo que se hará, siguiendo el proceder usual en ética, sobre la base de la definición del término bueno. Aunque vale aclarar que este orden no implica que la definición

\footnotetext{
30 Véase MaCKIE (1977) p. 9.

31 MaCKIE (1977) p. 9.

32 Austin (1962) pp. 98 ss.

33 Véase Broad (1930) pp. 116 ss. y 143 ss.; Anscombe (1958a) pp. 1 ss.
} 
del término bueno sea un paso lógico previo a la transición entre ser y deber, y que si aquí se le da prioridad temporal es solo por razones didácticas ${ }^{34}$.

\section{DEFINICIÓN DE BUENO}

Por lo menos desde la obra de G.E. Moore, cualquier intento de definición del término bueno debe dar respuesta a dos tipos de problema: la falacia naturalista y el argumento de la cuestión abierta ${ }^{35}$. Antes de él, por supuesto, muchos otros pensadores se ocuparon de la definición de bueno, entre ellos Kant ${ }^{36}$. La alusión a Kant, sin embargo, tiene un propósito delimitador, en la medida en que la filosofía práctica kantiana entiende a la moral principalmente como un sistema de deberes del cual se derivarían de manera inmediata los cursos de acción debidos, mientras que aquí, por el contrario, se parte del presupuesto de entender la moral como un sistema de razones que operan sobre una base empírica ${ }^{37}$. Además, porque aquí se parte de la independencia e irreducibilidad de los distintos tipos de conocimiento (el conocimiento de lo subjetivo, de lo intersubjetivo y de lo objetivo ${ }^{38}$, mientras que el método idealista kantiano cree poder reducir todo a la subjetividad del individuo con su fórmula de los juicios sintéticos a priori para la razón pura ${ }^{39}$ y su fórmula del imperativo categórico para la razón práctica ${ }^{40}$. En relación con esto último opina $\mathrm{Kant}^{41}$ : "No es posible pensar nada a lo largo del mundo, ni aún siquiera por fuera de él, que sin limitaciones pueda ser tenido por bueno, con la única excepción de la buena voluntad".

Expuesto a muy grandes rasgos, para Kant lo bueno es aquello que es prácticamente necesario. A su turno, lo prácticamente necesario es reconocido a priori por la razón práctica, que no es otra cosa que la voluntad. Esto sucede mediante la adecuación de la voluntad a leyes objetivas, las que, a su turno, están regidas por un principio objetivo o mandato de la razón, el cual se expresa mediante un imperativo ${ }^{42}$. La buena voluntad tiene, entonces, una bondad intrínseca que hace que lo bueno sea en sí mismo una razón de lo bueno. Ahora, debe abonársele a Kant el que haga un esfuerzo por hacer inteligible una exigencia que pareciera estar latente en el uso ordinario del pensamiento moral, a saber, la determinación de un punto fijo e inamobible del cual derivar todos los requerimientos morales y que al mismo tiempo fuera un requerimiento moral $^{43}$. En este sentido, su segunda formulación del imperativo catégorico, si bien no la más conocida, es pieza decisiva de su pensamiento ${ }^{44}$.

\footnotetext{
34 En igual sentido Hare (1952) p. 79 ss. y 151 ss.; MaCKIE (1977) pp. 50 ss.

35 Véase G.E. Moore (1903) pp. 10 y 15.

36 Véase Kant (1911b) Tomo IV, pp. 393 ss. y 412 ss.

$37 \mathrm{Al}$ respecto véase BirnBACHER (2007) pp. 136 ss. y 161.

38 Al respecto véase DAVIDSON (2001b) pp. 205 ss.

39 Véase Kant (1911a) Tomo III, pp. 39 ss.

40 Véase Kant (1911b) Tomo IV, p. 416.

41 Kant (1911b) Tomo IV, p. 393.

42 Véase Kant (1911b) Tomo IV, pp. 412 ss.

43 Véase Mackie (1977) pp. 59 ss.

44 Véase Kant (1911b) Tomo IV, p. 429: "Actúa de forma tal que todo el tiempo utilices a la humanidad, tanto en tu persona como en la persona de cualquier otro, al mismo tiempo como fin y nunca solo como medio".
} 
Sin embargo, este intento de fundar la moral ajeno a razones de experiencia puede llevar, como muy bien lo anota $\mathrm{Geach}^{45}$, a un sistema de respuestas circulares. Entonces, para que "no es bueno" no sea una respuesta suficiente a la pregunta “'por qué no es bueno?” se requiere un enfoque distinto al kantiano. Por esta razón de principio no se abordará aquí el análisis kantiano de lo bueno ${ }^{46}$.

Volviendo a G.E. Moore y sus objeciones de falacia naturalista y argumento de la cuestión abierta, se tiene que de conformidad con lo primero, definir bueno mediante proposiciones descriptivas confunde las cosas que son buenas con la bondad misma. Es importante resaltar que G.E. Moore no parte de la falacia naturalista como un principio metodológico ${ }^{47}$, sino que llega a ella como una conclusión tras su intento (frustrado) de definir el término bueno: “bueno' no tiene definición porque es algo simple y no tiene partes" ${ }^{4}$. Dado, entonces, que para G.E. Moore lo bueno solo podía ser algo simple e indefinible, y que ese algo debía ser una cualidad no natural ${ }^{49}$, resulta comprensible que tildara de falaz cualquier descripción de lo bueno. Debe abonársele a G.E. Moore que las cosas de las que se predica bondad y la bondad son cosas distintas entre sí, y solo una definición de lo segundo constituye lo bueno. Bajo este entendido la falacia naturalista es correcta. Pero si de lo que se trata es de trazar una mera distinción entre hechos morales y hechos de cualquier otro tipo, entonces es una visión que trivializa las definiciones de descriptivo y evaluativo, como se mostrará más adelante ${ }^{50}$. A su turno, el argumento de la cuestión abierta dice que ninguna definición del término bueno cierra las puertas a la pregunta posterior acerca de la bondad de aquello que así se define. Por ejemplo, aunque se tome la definición de bueno como ayudar al prójimo, y aunque se reconozca que $\mathrm{X}$ conduce a la ayuda del prójimo, aún así queda abierta la pregunta sobre si $\mathrm{X}$ es realmente bueno, y esto valdría para cualquier definición.

Estas objeciones, como muy bien lo destaca Mackie ${ }^{51}$, aplican particularmente al significado moral de bueno. Sin embargo, el término bueno en español tiene un uso moral y un uso no moral, al igual que sucede en otros idiomas (por ejemplo good en inglés y gut en alemán), y comoquiera que no resulta plausible asignarle a dicho término un significado moral desconectado de su significado no moral, es conveniente, antes que nada, "encontrar o un único significado general que la palabra tenga en los contextos moral y no-moral, o por lo menos un significado particular del cual sus otros significados sean consecuencia" 52 .

\footnotetext{
45 Geach (1956) pp. 39 ss.

46 Una interpretación de Kant que intenta salvar este problema la ofrece Brandom, quien propone sustituir ley por compromiso en su análisis de la voluntad racional; véase BRANDOM (2000) p. 94.

47 Así lo hace, sin embargo, Ferrajoli (1995) pp. 220, 241, 323 ss., 359 y 921; igualmente SuÁrez (2010) pp. 32 ss.

48 G.E. MoOre (1903) p. 9.

49 G.E. Moore (1903) pp. 7, 17 y 21.

50 Se trata de la idea de Austin, según quien descripción y evaluación son fuerzas ilocucionarias de una declaración que no se dejan reducir, en el caso de la descripción, a la dicotomía verdadero/falso, ni a la dicotomía valor/hecho, en el caso de la evaluación; véase Austin (1962) pp. 147-149; en igual sentido FLEW (1964) p. 27.

51 MaCKIE (1977) p. 51.

52 MaCKIE (1977) pp. 51 ss.
} 
En este sentido, es mérito de Geach ${ }^{53}$ haber sido el primero en aplicar la distinción entre adjetivos atributivos y adjetivos predicativos al estudio del significado del término bueno ${ }^{54}$. Según él, la dificultad en definir bueno radica en que bueno es, en términos lógicos (no gramaticales), lo que él llama un adjetivo atributivo: “'bueno' y 'malo' son siempre adjetivos atributivos, no predicativos" $"$.

Un ejemplo familiar de cómo opera un adjetivo atributivo es el siguiente: "X es una pulga grande". Aquí grande tiene el rol de adjetivo atributivo, con la siguiente consecuencia: de la proposición "X es una pulga grande" no se deriva "X es una pulga y X es grande", de la misma forma como de la proposición "X es un elefante pequeño" no se deriva "X es un elefante y X es pequeño". Porque si esta derivación fuera posible, entonces habría que afirmar que una pulga grande es un animal grande y que un elefante pequeño es un animal pequeño, lo que resulta contraevidente ${ }^{56}$. Otros ejemplos son los siguientes: "X es el padre putativo de A", de donde no se deriva "X es el padre de $\mathrm{A}$ y $\mathrm{X}$ es putativo" o "X es un buen $\mathrm{A}$ " (con total independencia de qué sea $\mathrm{A}$ ), de donde no se deriva "X es bueno y $\mathrm{X}$ es $\mathrm{A}$ ". Por el contrario, un ejemplo de adjetivo predicativo es el siguiente: "X es un libro rojo". Aquí rojo tiene el rol de adjetivo predicativo, con la siguiente consecuencia: de la proposición "X es un libro rojo" se sigue que "X es un libro y X es rojo" ${ }^{57}$. El siguiente test permite distinguir un tipo de adjetivos del otro: "si ' $\mathrm{C}$ ' es predicativo, entonces, si $x$ es ambas cosas, $\mathrm{A}$ y $\mathrm{B}$, se tiene que si $x$ es CA entonces $x$ tiene que ser también $\mathrm{CB}$; pero si ' $\mathrm{C}$ ' es atributivo y $x$ es ambas cosas, $A$ y B, $x$ puede ser CA pero no CB" ${ }^{58}$. De conformidad con este test, bueno es un adjetivo atributivo, puesto que una persona que sea abogado y barista puede ser buen abogado y no ser buen barista. Este razonamiento le permite a Geach sostener que el término bueno tiene primariamente una fuerza descriptiva ${ }^{59}$. Los adjetivos atributivos, bajo este entendido, serían aquellos que "construyen nuevas descripciones de forma sistemática por fuera del significado de los sustantivos a los que están atados"60.

Pese a la importancia de este aporte, la determinación de bueno como un adjetivo atributivo aún no contesta la pregunta de cómo es atributivo, es decir, qué tipo de operación realiza el término bueno sobre los predicados a los cuales está atado ${ }^{61}$. Un primer intento de respuesta a este interrogante viene dado por Hare, quien parte del supuesto según el cual bueno tiene un significado primariamente evaluativo y solo secundariamente descriptivo $^{62}$. En apoyo de esta tesis introduce la distinción entre palabras funcionales y palabras no funcionales, así: "Una palabra es una palabra funcional si, en orden a explicar su

53 GeACH (1956) pp. 33 ss. El trasladado de este pensamiento al derecho penal, en especial en lo referente a la definición de bien jurídico, puede verse en KINDHÄUSER (1989) pp. 140 ss.

54 Posteriormente Quine hablará de adjetivos sincategoremáticos; véase QuINE (1960) p. 103.

55 GEACH (1956) p. 33.

56 Véase GEACH (1956) p. 33.

57 Véase GEACH (1956) p. 33.

58 MACKIE (1977) p. 52.

59 Véase GEACH (1956) p. 36.

60 Mackie (1977) p. 52. Por esta razón Mackie los llama "operadores en predicados".

61 Véase MACKIE (1977) p. 53.

62 Véase Hare (1952) p. 118; el mismo (1957) pp. 106 ss. 
significado completo, nosotros tenemos que decir para qué es el objeto al que nos referimos con ella, o qué se supone que hace" ${ }^{33}$. De esta forma, cuando bueno está asociado a una palabra funcional no hay ningún problema en reconocer el significado descriptivo de bueno ${ }^{64}$. Ejemplos de palabras funcionales son, entre otras, taladro y cuchillo, pues su definición siempre incluirá la referencia a la función desempeñada por dichos objetos. De esta forma, conociendo el significado de taladro se estaría en la posibilidad de saber qué rasgos debe tener un taladro para ser definido como un buen taladro. De otra parte, asociar bueno a taladro significa que el taladro tiene las características que le permiten desarrollar su función ${ }^{65}$. Por el contrario, frente a las palabras no funcionales el término bueno no tiene significado descriptivo, pues en estos casos no basta con conocer la definición del objeto para saber si el mismo es susceptible de definirse como bueno. Un ejemplo de palabra no funcional es atardecer, pues aquí no basta con conocer el significado de atardecer para saber qué rasgos debe tener un atardecer que haya de ser definido como bueno. En estos casos es necesario "conocer qué estándar ha de ser adoptado para juzgar la bondad de este tipo de cosas; y este estándar no nos es revelado, ni siquiera en parte (como en el caso de las palabras funcionales), por el significado de la palabra asociada a 'bueno'"66.

La anterior reflexión le permite a Hare concluir que la definición general de bueno no puede ser descriptiva, dado que ello dejaría por fuera de su uso las palabras no funcionales. Por eso propone una definición de bueno susceptible de asociarse tanto a palabras funcionales como a palabras no funcionales. Bajo dicha definición la primera función del término bueno es elogiar ${ }^{67}$. Bajo este supuesto, entonces, bueno significa "tener las cualidades características (independientemente de lo que se trate) que son encomiables en la clase de objeto en cuestión" ${ }^{68}$. Es decir, según Hare el elogio es el punto que une los varios usos de bueno. Elogiar, a su turno, es mencionar que algo es bueno ${ }^{69}$. De allí que, como pone de presente $\mathrm{Mackie}^{70}$, si bien esta definición no es falsa, sí es circular y no dice nada nuevo en la medida en que define lo bueno en términos del elogio, y el elogio en términos de lo bueno.

Del aporte de Hare debe destacarse el intento por formular una definición general de bueno que abarque tanto a las palabras funcionales como a las no funcionales. El punto a superar es, entonces, la circularidad de su definición. Un primer paso para superar esta circularidad viene dado por lo que Mackie denomina el elogio egocéntrico. Según éste, elogiar algo "es decir que la cosa satisface ciertos requerimientos, mientras que al mismo tiempo se indica que se aprueban dichos requerimientos" ${ }^{\prime 1}$. Sin embargo, este elogio egocéntrico se queda corto en la medida en que es hecho desde el punto de vista del hablante, y existen situaciones

\footnotetext{
63 Hare (1952) p. 100, bastardillas en el original; acerca de las palabras funcionales y la dicotomía entre hecho y valor véase CRAGG (1976) pp. 77-94.

64 Véase Hare (1957) p. 107.

65 Véase Hare (1952) pp. 100 ss.; el mismo (1957) p. 107.

66 Hare (1957) p. 108.

67 Hare (1952) p. 127.

68 HaRe (1957) p. 108.

69 Hare (1957) p. 106.

70 MaCKIE (1977) p. 54.

71 Mackie (1977) p. 54.
} 
en las que el hablante puede reconocer algo como bueno sin tener por ello que elogiarlo ${ }^{72}$. Un vegetariano, por ejemplo, puede decir de una carne que es una buena carne así no lo encuentre encomiable, o un no aficionado al fútbol puede reconocer que Diego Armando Maradona fue un buen jugador de fútbol así no lo encuentre encomiable. La existencia de esta posibilidad, no obstante, demuestra que el elemento común a estas situaciones de elogio es la presencia de un "cierto set de requerimientos o deseos o intereses", y que de aquello que es definido como bueno "se puede decir que es apto para satisfacer esos requerimientos o deseos o intereses"73. Este descubrimiento le permite a Mackie ofrecer la siguiente definición general de bueno: "apto para satisfacer requerimientos (etc.) de la clase en cuestión"74.

La primera parte de la definición (apto para satisfacer) no se deja sustituir por satisface por dos razones. Primero, porque "basta con que la cosa sea de tal forma, que ella satisfaga deseos, intereses y requerimientos de la clase indicada si alguien se concentrara en relacionarlos con ella"75. De esta forma, un cuchillo seguirá siendo un buen cuchillo aun cuando nunca sea usado o incluso necesitado. Segundo, porque "al llamar algo bueno estamos diciendo algo acerca de cómo es en sí mismo; nos estamos refiriendo inmediatamente a sus cualidades, sus rasgos intrínsecos, antes que referirnos directamente a cualquier relación que ese algo tenga con cualquier cosa, como sucedería si dijéramos que ese algo satisface algún interés"76. La segunda parte de la definición (requerimientos etc. de la clase en cuestión) es deliberadamente vaga a fin de que cubra diferentes usos del término bueno. De esta forma "deja abierto precisamente cómo están especificados o indicados los requerimientos en cuestión" y, de la misma manera, "deja espacio para requerimientos que han de ser usados de diferentes maneras y en diferentes tipos de caso" 77 .

Ya fue dicho antes que no resulta plausible asignarle al término bueno un significado moral desconectado por completo de su significado no moral. Entonces, dada la definición general del término bueno se tiene que su uso moral implica también la existencia de un cierto set de requerimientos etc. junto con la aptitud de aquello que se defina como bueno para satisfacer dichos requerimientos. Esto significa que no le asiste razón a G.E. Moore al pensar que bueno es un término indefinible y ajeno por completo a proposiciones descrip$\operatorname{tivas}^{78}$. Entonces, si la falacia naturalista se entiende como la prohibición de incluir proposiciones descriptivas en la definición del término bueno, ella es falsa. Esta comprensión de la falacia naturalista corresponde, por lo demás, a una visión que trivializa las definiciones de descriptivo y evaluativo, pues aunque la misma sea una excelente forma de trazar una distinción clara entre hechos morales y hechos de cualquier otro tipo, tiende también a obviar el carácter (lógico) atributivo de las proposiciones evaluativas demostrado por Geach.

Pero, ¿escapa este uso moral del término bueno al argumento de la cuestión abierta?. De conformidad con el argumento de la cuestión abierta, como ya se expuso, ninguna de-

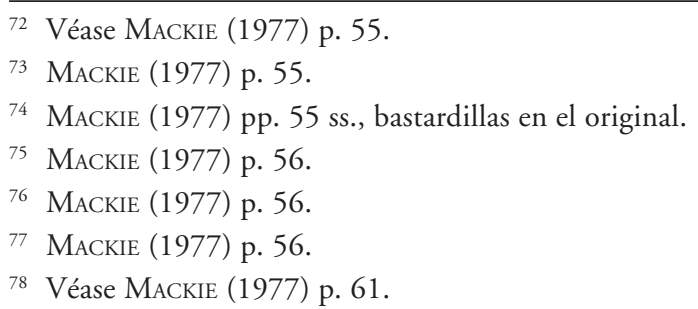


finición del término bueno cierra las puertas a la pregunta posterior acerca de la bondad de aquello que así se define. Entonces, aun cuando se definiera bueno como ayudar al prójimo y se supiera que $\mathrm{X}$ conduce a la ayuda del prójimo, aún así se podría plantear la pregunta acerca de si $\mathrm{X}$ es realmente bueno. Pero si se tiene que $\mathrm{X}$ conduce a la ayuda del prójimo, y aún así se pregunta sobre la bondad de X, se pone de manifiesto que con la pregunta se está haciendo alusión a otros requerimientos distintos a aquellos que X está en capacidad de satisfacer. Por ello le asiste razón a Hare ${ }^{79}$ cuando destaca que la fuerza del argumento de la cuestión abierta descansa en el siguiente presupuesto: si equiparáramos bondad con cualquier set de características definidas, entonces no podríamos elogiar algo por el solo hecho de poseer dichas características. Si este elogio es parte del uso moral del término bueno, entonces él ha de ser algo distinto de la bondad misma.

El elogio egocéntrico, como ya se dijo, permite romper esa circularidad pues él consiste en decir que la cosa satisface ciertos requerimientos, mientras que al mismo tiempo se indica que se aprueban dichos requerimientos. Este último punto, es decir el respaldo a los requerimientos, es la clave para replicar al argumento de la cuestión abierta: si se define lo bueno como ayudar al prójimo y $\mathrm{X}$ equivale a ayudar al prójimo, entonces $\mathrm{X}$ será bueno en la medida en que haya razones para respaldar la ayuda al prójimo. Estas razones, por supuesto, no tienen que ser egocéntricas ${ }^{80}$, y de hecho no lo son, pues pertenece a la gramática de la moral el que sus prescripciones sean universales ${ }^{81}$. De aquí se concluye que el uso moral del término bueno tiene, aparte de su significado descriptivo, también un significado prescriptivo $^{82}$. Es decir, bueno en el contexto moral tiene el mismo significado descriptivo que el término posee en su uso no moral, el cual viene dado por la satisfacción de la relación entre los requerimientos en cuestión y aquello que se define como bueno. Y adicionalmente a ello tiene también un significado prescriptivo, el cual viene dado por el respaldo que se le dé a los requerimientos en cuestión ${ }^{83}$. El uso moral de bueno, de esta forma, posee una fuerza ilocucionaria de respaldo. En consecuencia todo aquel que afirme, en el uso moral del término, que $\mathrm{X}$ es bueno, siendo $\mathrm{X}$ equivalente con ayudar al prójimo, es porque reconoce la existencia de razones que respaldan la bondad de ayudar al prójimo.

$\mathrm{Al}$ anterior razonamiento se le podría objetar que, de alguna manera, no escapa al argumento de la cuestión abierta en la medida en que solo desplaza el lugar donde se ubica la cuestión abierta: antes en la pregunta por lo bueno y ahora en la pregunta por las razones que respaldan los requerimientos en cuestión. Entonces, dado que la expresión set de requerimientos de la clase en cuestión es deliberadamente vaga, ¿cómo se puede cerrar o, al menos, reducir la vaguedad del significado del término bueno? La respuesta a esta pregunta exige un estudio sobre el estatus ontológico de los requerimientos en cuestión y, en particular, del tema de su objetividad o subjetividad. La importancia del tema estriba, en lo que aquí concierne, en que se suele afirmar que la posibilidad de reconocer un carácter objetivo

\footnotetext{
9 Véase Hare (1952) pp. 83 ss.

Véase Mackie (1977) pp. 60 ss.

81 Al respecto véase BirnBaCher (2007) pp. 31 ss.

82 Véase Mackie (1977) pp. 60 ss.

83 Véase Mackie (1977) pp. 61 sp.
} 
en los requerimientos en cuestión lleva, en el plano de la moral, al reconocimiento de valores morales objetivos, y esto último, a su turno, permitiría poner el uso moral de bueno a salvo del argumento de la cuestión abierta. Esta decisiva cuestión merece un desarrollo pormenorizado y, por lo tanto, no será abordado aquí ${ }^{84}$. Omitir este punto, sin embargo, no afecta los objetivos trazados para el presente artículo, dado que el respaldo que constituye el significado prescriptivo del uso moral del término bueno, como ya se dijo, no puede ser un respaldo egocéntrico. Eliminada la subjetividad, solo bastaría fundamentar la forma en que pueden ser reconocidos valores morales objetivos (lo que, se repite, no será desarrollado aquí).

\section{TRANSICIÓN DEL SER AL DEBER}

Antes se hizo ya referencia a una supuesta ley de Hume con el contenido: Está prohibido pasar de una premisa descriptiva a una conclusión prescriptiva. Pero, ¿existe realmente tal prohibición en Hume? Como bien lo afirma MacIntyre ${ }^{85}$, la relación entre aserciones de hecho y juicios morales planteada por Hume es uno de aquellos temas que, en la historia de la filosofía, ha quedado rígidamente fijado en la discusión, y en este caso sobre el supuesto equivocado de una tal prohibición. Para desvirtuar ese supuesto equivocado, nada mejor que oír lo que dijo Hume:

"In every system of morality, which I have hitherto met with, I have always remark'd, that the author proceeds for some time in the ordinary way of reasoning, and establishes the being of a God, or makes observations concerning human affairs; when of a sudden I am surpriz'd to find, that instead of the usual copulations of propositions, is, and is not, I meet with no propositions that is not connected with an ought, or an ought not. This change is impercetible; but is, however, of the last consequence. For as this ought, or ought not, expresses some new relation or affirmation, 'tis necessary that it shou'd be observ'd and explain'd; and at the same time that a reason should be given, for what seems altogether inconceivable, how this new relation can be a deduction from others, which are entirely different from it. But as authors do not commonly use this precaution, I shall presume to recommend it to readers; an am persuaded, that this small attention wou'd subvert all the vulgars systems of morality, and let us see, that the distinction of vice and virtue is not funded merely on the relations of objects, nor is perceiv'd by reason" 86 .

Lo primero que hay que decir sobre este pasaje es que Hume afirma ser testigo de cambios imperceptibles que tienen lugar en el uso ordinario de razonamientos. Estos cambios imperceptible se presentan entre proposiciones cuya cópula es "es" o "no es" y aquellas cuya cópula es "debe" o "no debe". Estas últimas proposiciones, afirma Hume, expresan una nueva relación, lo que hace necesario, según él, dar una razón que explique dicho cambio, el cual, de otra forma, sería inconcebible dada la diferencia entre los distintos tipos de

${ }^{84}$ Cómo puede reconocerse objetividad en el tema de los valores puede verse en PUTNAm (2002) pp. 7-45; el mismo (2004) pp. 15-32; véase también DAVIDSON (2004) pp. 39 ss. y 52 ss.

85 Véase MacIntyre (1959) p. 451.

86 Hume (1949) pp. 469 ss., bastardillas en el original. 
relación ${ }^{87}$. Notable resulta también su afirmación final, según la cual notar estos cambios impercetibles subvertirá los sistemas vulgares de moralidad.

Del párrafo anterior debería concluirse que Hume es lo suficientemente claro y que no hay razón para atribuirle una prohibición de transición, sino simplemente la exigencia de justificación. ¿Por qué entonces se habla de la ley de Hume en el sentido de una prohibición? Un primera explicación ${ }^{88}$ parte de asumir que según Hume los argumentos son o deductivos o defectuosos, tal como se desprendería de su escepticismo acerca de la inducción ${ }^{89}$. De esta forma la proposición prescriptiva no sería más que una conclusión deductiva donde la proposición descriptiva sería la premisa menor y solo haría falta una proposición adicional como premisa mayor para justificar el paso ${ }^{90}$. Así, por ejemplo, para justificar el tránsito de la aserción de hecho "A mató a B" (premisa menor) al juicio moral "A debe ser sancionado" (conclusión) solo haría falta otro juicio moral del siguiente tenor: "Aquel que mate a otro debe ser sancionado" (premisa mayor). De igual forma, para pasar de "la olla con agua lleva 10 minutos en el fuego" (premisa menor) a "el agua debe estar hirviendo en este momento" (conclusión), solo haría falta la regla "siempre que la olla con agua lleve 10 minutos en el fuego, el agua hierve” (premisa mayor).

Ahora, es bien sabido que el escepticismo de Hume acerca de la inducción descansa en la exigencia errónea según la cual la inducción debe ser mostrada como una forma de deducción ${ }^{91}$. De conformidad con dicha exigencia, entonces, resulta evidente que en ausencia de un método inductivo y de una premisa mayor no habría posibilidad de tránsito entre la proposición descriptiva y la proposición prescriptiva. De otra parte, como bien lo anota MacIntyre" mayor envuelve en sí misma una aserción inductiva que requiere de justificación”. Con otras palabras: si para justificar el paso de la premisa menor (la proposición descriptiva) a la conclusión (la proposición prescriptiva) se introduce una premisa mayor sin justificación alguna, dicho procedimiento solo implicará un cambio del paso a justificar, pero no una justificación, y así se podría extender el procedimiento hasta el infinito. Con ello solo quedarían dos posibilidades: o es imposible el tránsito de una proposición descriptiva a una prescriptiva en ausencia de inducción y de la premisa mayor o, aún disponiendo de un método inductivo, dicho tránsito es injustificable en la medida en que regresa al infinito. Si éste es el entendimiento de la ley de Hume, entonces es cierto que ella prohiba el paso de una proposición descriptiva a una prescriptiva.

Sin embargo una interpretación más fiel a Hume, es decir una interpretación que tenga en cuenta el párrafo ya transcrito, donde no se dice expresamente que sea prohibido pasar de una proposición descriptiva a una prescriptiva, y que también tenga en cuenta otros pasajes de su obra donde expresamente se pasa de proposiciones descriptivas a pro-

\footnotetext{
87 En igual sentido MacIntyre (1959) pp. 459 ss.; véase también FleW (1964) pp. 27 ss.; MACKIE (1977) pp. 64 ss.

${ }^{88} \mathrm{Al}$ respecto véase MacInTyRe (1959) pp. 453 ss.; sobre Hume y la inducción véase GoOdman (1983) pp. 59-62.

89 Véase Hume (1949) p. 89.

90 Así Hare (1952) pp. 56 ss.

91 Véase MacIntyre (1959) p. 453.

92 Macintyre (1959) p. 454.
} 
posiciones prescriptivas, servirá para refutar el argumento basado en el escepticismo acerca de la inducción. Pues Hume, al tratar el tema de la justicia, da el paso de una proposición descriptiva a una prescriptiva, así: para Hume llamar un acto justo o injusto significa decir que el mismo cae bajo una regla. Ahora, y esto es lo importante, según él esto debe ser así, es decir, debe haber reglas de justicia, porque "sin justicia la sociedad habrá de disolverse inmediatamente y cada uno habrá de caer en una condición salvaje y solitaria, la cual es infinitamente peor que la peor situación que es posible suponer en sociedad"93. Entonces, de la premisa descriptiva "la obediencia a las reglas de justicia es beneficiosa" se pasa a la premisa prescriptiva "debe haber reglas de justicia" 94 . Con ello, de ser cierto que Hume planteó una prohibición de tránsito del ser al deber, es también cierto que fue el primero que la quebrantó ${ }^{95}$. Dado que no es razonable ${ }^{96}$ atribuirle esta última convicción a la luz de sus convicciones referentes a la justicia, debe concluirse que Hume nunca planteó la prohibición que se le atribuye. La así denominada ley de Hume, entonces, debe entenderse como la necesidad de justificar el tránsito de una proposición descriptiva (ser) a una proposición prescriptiva (deber).

Un desafío en apariencia más interesante es el planteado por la posición de Searle ${ }^{97}$, quien, con el entendimiento usual de la ley de Hume a la base, cree haber podido deducir el deber a partir del ser. Su argumento parte de presentar el siguiente ejemplo, según él contraintuitivo:

Jones pronunció las palabras "yo, por medio del presente acto, prometo pagarte a ti, Smith, cinco dólares".

1. Jones prometió pagarle a Smith cinco dólares.

2. Jones se puso a sí mismo en la obligación de pagarle a Smith cinco dólares.

3. Jones está bajo la obligación de pagarle a Smith cinco dólares.

4. Jones debe pagarle a Smith cinco dólares ${ }^{98}$.

Asumiendo un carácter ceteris paribus para cada una de estas oraciones, se tiene que la oración 2 se deriva de la oración 1, la 3 de la 2, la 4 de la 3 y, finalmente, la 5 de la 4 , siendo la oración 1 una oración descriptiva y sin que sea necesario agregar oración prescriptiva alguna para que las sucesivas oraciones se deduzcan de las que inmediatamente les anteceden. Es decir, la oración 1 contiene la 2, la 2 la 3, la 3 la 4 y la 4 la $5^{99}$. Ahora, la oración 1 contiene la oración 2 en virtud del significado especial de las palabras "yo, por medio del presente acto, prometo...", las que constituyen el acto de prometer, mientras que el paso desde la oración 2 a la 5 es mediado por tautologías. Esta cadena de razonamientos

\footnotetext{
93 Véase Hume (1949) p. 497; acerca de esta interpretación véase MacInTYRE (1959) pp. 456 sp.

94 Parcialmente en contra MacIntyre (1959) p. 457, quien considera necesario reemplazar la expresión "es beneficiosa" de la premisa descriptiva por la expresión "es consensuada".

95 Véase Macintrre (1959) p. 457.

96 Acerca de los principios de racionalidad a la hora de atribuir convicciones y sobre el carácter "reivindicable" de las mismas véase DAVIDSON (2001b) p. 211.

97 Véase Searle (1964) pp. 43 ss.; el mismo (1969) pp. 175 ss.

98 SeArle (1969) p. 177.

99 Véase Searle (1969) pp. 177 ss.
} 
le permite concluir a Searle ${ }^{100}$ lo siguiente: "Así, hemos derivado (en el estricto sentido que 'derivar' admite en el lenguaje natural) un 'deber' de un 'ser'”. El punto central del argumento de Searle es que, según él, el modelo clásico de derivación del deber como conclusión lógica de un silogismo práctico es "incapaz de tratar con hechos institucionales" Así, prometer algo es un hecho, pero este hecho tiene carácter institucional, es decir, no es un mero hecho bruto ${ }^{102}$. Esta distinción entre hechos brutos y hechos institucionales sería, entonces, la llamada a salvar la brecha entre descripción y prescripción. Pues a cada hecho institucional subyace una regla o un sistema de reglas de la forma "X cuenta como Y en el contexto C”, y el carácter de estas reglas es constitutivo en la medida en que las instituciones son sistemas de reglas constitutivas ${ }^{103}$. De allí que la prueba de su deducción descanse en la siguiente regla constitutiva: "hacer una promesa es ponerse bajo una obligación, y esta regla es una regla de significado de la palabra 'descriptiva' 'promesa'”104.

Sin embargo, como Mackie ${ }^{105}$ correctamente demostró, el argumento de Searle pone de presente dos formas de hablar: una forma de hablar por fuera de la institución y una forma de hablar con la institución. Desde fuera la institución puede ser descrita, por ejemplo, se puede reconocer que hay una práctica social llamada promesa, la cual tiene como uno de sus elementos el que se le puedan hacer ciertas demandas a aquellos que participan de la práctica. De esta forma se puede decir, desde fuera, que la institución de la promesa exige que se guarden las promesas. Hablar con la institución, por el contrario, implica invocar la institución y no simplemente reportar sus características. De esta forma se puede decir, con la institución, que si alguien promete algo debe cumplir lo prometido, justamente porque prometió. Ahora, lo que aquí interesa resaltar es que con independencia de cómo se mire la institución, desde fuera o desde dentro, ambas formas de hablar son materia de la lógica, así: para la forma de hablar desde fuera de la institución vale una lógica general cuyas premisas y conclusiones se refieren a hechos brutos, mientras que para la forma de hablar con la institución vale una lógica especial cuya especialidad radica en que sus premisas y conclusiones se refieren a hechos institucionales ${ }^{106}$.

Entonces, si hablando por fuera de la institución de la promesa se dice que "Jones debe pagarle a Smith cinco dólares" se está haciendo alusión a un hecho bruto, razón por la cual no emerge problema alguno de relación entre proposiciones descriptivas y proposiciones prescriptivas. Por su parte, si hablando con la institución de la promesa se dice que "Jones debe pagarle a Smith cinco dólares" se está haciendo alusión a un hecho institucional, lo que significa que dicha proposición prescriptiva no se obtiene directamente de las oraciones 1 a 4 que le anteceden, sino que se obtiene de dichas oraciones y de las reglas

\footnotetext{
100 Searle (1969) p. 181.

101 SeARle (1969) p. 184.

102 Sobre la distinción entre hechos brutos y hechos institucionales véase SEARLE (1969) pp. 50 ss.; véase también Anscombe (1958b) pp. 69 ss.

103 SEARLE (1969) pp. 51 ss.; sobre la distinction entre reglas regulativas y reglas constitutivas véase SEARLE (1969) pp. 33 ss.

104 SeARle (1969) p. 185.

105 Véase Mackie (1977) pp. 67 ss.

106 Véase Mackie (1977) pp. 67 ss.
} 
que rigen la institución de la promesa (lógica especial) ${ }^{107}$. Ahora, como muy bien lo destaca Mackie $^{108}$, "puede ser peligrosamente desorientador hablar de hechos institucionales si después se van a presentar juntas estas dos interpretaciones". De lo anterior surge evidente que el error de Searle radica en tomar la conclusión "Jones debe pagarle a Smith cinco dólares" como hecho institucional y pretender que ella se deriva de las oraciones 1 a 4, tomadas como referidas a hechos brutos, solo en virtud de la lógica general ${ }^{109}$. De esta forma, Searle pierde de vista que su derivación del deber, entendido este deber como un hecho institucional, también es fruto de un silogismo práctico, aun cuando dicho silogismo esté regido aquí por una lógica especial.

Del análisis del argumento escéptico acerca de la inducción y del argumento de Searle queda claro que sí hay una relación entre proposiciones descriptivas y proposiciones prescriptivas. Por tanto, el entendimiento usual de la ley de Hume, según el cual estaría prohibido pasar de una a otra, es una comprensión que trivializa el asunto, pues el punto crucial no es trazar una distinción entre ser y deber, sino saber cuándo y cómo existe una relación entre uno y otro. Abordar este asunto implica delinear una teoría que justifique el tránsito del ser al deber. Para ello, en primer lugar, debe ponerse de presente que el término deber, al igual que el término bueno, tiene en castellano un uso moral y un uso no moral, como también sucede en otros idiomas (por ejemplo ought en inglés y sollen en alemán), y que aquí tampoco resulta plausible asignarle a dicho término un significado moral desconectado de su significado no moral.

En este contexto el significado general del término deber es el siguiente: hay una razón para la prescripción. En palabras de Mackie ${ }^{110}$, el equivalente general de " $a$ debe ser G" es "hay una razón para que a sea G”. Ahora, contrario a lo que opina Mackie ${ }^{111}$, no son los distintos usos de deber los que determinan las distintas clases de razones, sino las distintas clases de razones las que determinan los distintos usos de deber. Por este motivo tampoco le asiste razón cuando afirma que en el uso no moral del término deber el tránsito de la proposición descriptiva a la prescriptiva no constituye una nueva relación ${ }^{112}$. El origen de este error, sin duda, está en la posición escéptica defendida en moral por Mackie, pues la negación tajante de la existencia de valores morales objetivos ${ }^{113}$ parecería envolver una mayor dificultad en el uso moral de deber, cuyas razones habrían de ser construidas (las razones que justifiquen la nueva relación), frente a una menor dificultad en su uso no moral, donde las razones estarían ya fijadas en una regla (natural o social). Esto es errado, porque las reglas que soportan el paso de ser a deber en su uso no moral son reglas que también han sido construidas o descubiertas. Entonces, tanto en su uso moral como en su uso no moral el término deber establece siempre una nueva relación frente a la proposición descriptiva con que se encuentre asociada.

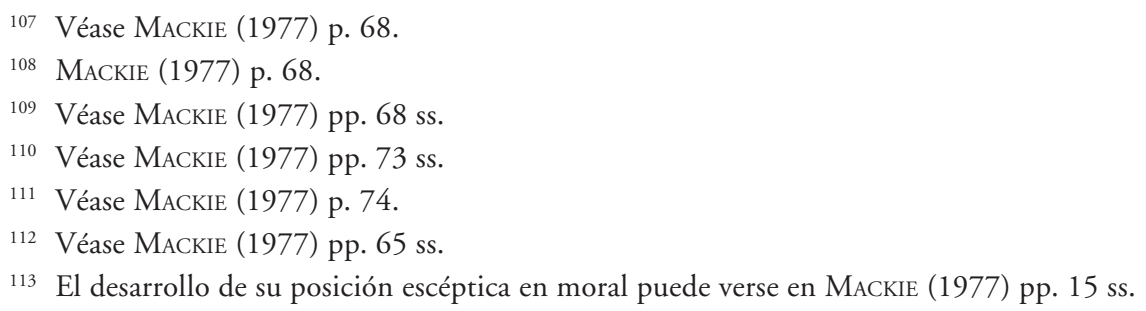


La reflexión anterior permite afirmar lo siguiente. La ley de Hume no prohibe el paso de una proposición descriptiva (ser) a una prescriptiva (deber), sino que establece la necesidad de justificar mediante razones el tránsito de una a otra. La razón justificante hace concebible el tránsito de la proposición descriptiva a la proposición prescriptiva en la forma de un silogismo práctico, donde la razón justificante opera como premisa mayor, la proposición descriptiva como premisa menor $y$, finalmente, la proposición prescriptiva como conclusión ${ }^{114}$. De esta forma, cuando se concluye que "el agua debe estar hirviendo en este momento", que "A debe ser castigado" o que "A debe ir hasta la nevera a recoger la cerveza" en presencia de las proposiciones "la olla con agua lleva 10 minutos en el fuego", "A mató a B" o "A desea tomarse una cerveza”, respectivamente, significa que hay una razón para que el agua esté hirviendo, una razón para que A sea castigado y una razón para que A vaya hasta la nevera a recoger la cerveza. Esta razón es la que media entre la proposición descriptiva y la prescriptiva y sin ella no es legítimo transitar de una a otra. Ahora, qué características ha de tener una razón para que sea considerada como una razón justificante es un tema que escapa a los objetivos del presente artículo ${ }^{115}$.

\section{IV. ¿SON LA LEY DE HUME Y LA FALACIA NATURALISTA LÍMITE DE ALGO EN DERECHO PENAL?}

Como ya se dijo en la sección I de este artículo, los defensores del neo-constitucionalismo y de la principialística pretenden presentar asuntos políticamente controvertibles como pre-políticos, propiciando así un debilitamiento de la democracia (Atria habla de un ciclo de la adjudicación ${ }^{116}$, Mañalich habla de la generación de una específica forma de falsa conciencia ${ }^{117}$ ). En lo que sigue pretendo poner de presente cómo el discurso neoconstitucionalista o principialista de Ferrajoli, más conocido como garantismo, asume esa estrategia de disimulación mediante el recurso a una forma sublimada de iusnaturalismo ${ }^{118}$. En particular me interesa, como ya anuncié, el uso que hace de la ley de Hume y de la falacia naturalista como límites del derecho penal.

Al tratar el tema de la separación entre derecho y moral, Ferrajoli apunta que la misma tiene, entre otros, un sentido asertivo, razón por la cual dicha separación debe entenderse como una "tesis meta-lógica -y concretamente una aplicación de la llamada ley de Hume- que veta en tanto que 'falacia naturalista' la derivación del derecho válido o 'como es' del derecho justo o 'como debe ser' y viceversa"119. A renglón seguido propone "llamar ideologías a todas las tesis y doctrinas viciadas por falacias semejantes" ${ }^{\prime 20}$. Y remata diciendo

\footnotetext{
114 Véase Hare (1952) pp. 56 ss.

115 Al respecto, desde una perspectiva intuicionista, véase Ross (1930) pp. 12, 29, 41 y 155-173; desde la perspectiva de la teoría del discurso véase Habermas (1983) pp. 60-86; en el ámbito jurídico véase M.S. Moore (2002) pp. 632 ss.

116 Véase Atria (2016) p. 104.

117 Véase Mañalich (2018) p. 62.

118 Así lo define Mañalich; al respecto véase Mañalich (2018) p. 63.

119 Ferrajoli (1995) p. 220, bastardillas en el original.

120 Ferrajoli (1995) p. 220, bastardillas en el original.
} 
que: "Por 'ley de Hume' se entiende la tesis según la cual no se pueden derivar lógicamente conclusiones prescriptivas o morales de premisas descriptivas o fácticas, ni a la inversa" ${ }^{" 21}$.

Un análisis detallado de esta cita de Ferrajoli arroja lo siguiente: de la proposición " $\mathrm{X}$ es derecho" (el derecho como es) no puede derivarse la proposición "X es derecho justo" (el derecho como debe ser). Es evidente que la relación que hay entre estas dos proposiciones no es aquella que existe entre una proposición que es cierta y otra que debería ser cierta, sino aquella relación que se presenta entre una proposición cuyo contenido está acompanado por una característica descriptiva y otra cuyo contenido está acompañado por una característica valorativa. De conformidad con lo expuesto arriba, entonces, la prohibición de pasar de una proposición a otra no vendría dada por la ley de Hume sino por la falacia naturalista. Esta crítica, por supuesto, puede entenderse como algo menor, y no en vano se suelen equiparar ambos conceptos. Por lo demás, debe abonársele a Ferrajoli el que guarde coherencia con su comprensión de este postulado y entienda (al igual que lo hacía G.E. Moore) el fundamento de la moral como algo subjetivo, no susceptible de ser conocido ${ }^{122}$. Las razones por las cuales esta comprensión es equivocada ya se expusieron en su lugar.

Un punto que por lo pronto resulta más espinoso que el anterior viene dado por la consecuencia que Ferrajoli extrae al aplicar aquí la falacia naturalista como límite. Dice así:

"En su virtud resultan excluídas de la 'ciencia jurídica positiva', en tanto que no fundadas empíricamente en el derecho positivo, todas las diversas definiciones sustancialistas del delito por medio de connotaciones ontológicas de tipo moral, natural, político o social en vez de meramente legales, así como las legitimaciones ideológicas del derecho penal conectadas con ellas"123.

Aquí hay un paso en falso. En efecto, la falacia naturalista prohibiría transitar de la proposición "X es derecho" (el derecho como es, la ciencia jurídica positiva) a la proposición "X es derecho y $\mathrm{X}$ tiene una determinada connotación valorativa" (el derecho como debería o no ser). Ahora, y aquí es donde está el paso en falso, eso no es lo mismo que afirmar: de la proposición "X es derecho" no se puede concluir la proposición "X es derecho y X tiene una determinada connotación valorativa", luego entonces "X no tiene una determinada connotación valorativa" ("las diversas definiciones sustancialistas del delito por medio de connotaciones ontológicas de tipo moral, natural, político o social en vez de meramente legales" excluidas por Ferrajoli). Que esto no es cierto se demuestra mediante un ejemplo contraintuitivo: de la proposición "está prohibido matar" no se puede concluir, de conformidad con la falacia naturalista, la proposición "matar es malo", luego entonces "matar no es malo". La razón de la equivocación de Ferrajoli estriba en que la existencia de una prohibición no contesta la pregunta relativa a si lo prohibido está o no dotado de una determinada connotación valorativa, con independencia de la prohibición lógica de pasar de premisas descriptivas a conclusiones valorativas, pues esto último no tiene nada que ver con lo primero, como ya se demostró. Lo que aquí falta son las razones que respalden (o no) la determinada connotación valorativa, y no la relación descriptiva entre la connota-

121 Ferrajoli (1995) p. 241.

122 Ferrajoli (1995) pp. 920 ss.

123 Ferrajoli (1995) p. 222. 
ción valorativa y aquello de lo cual se predica (o no) dicha connotación. Arriba se denominó esta característica como la fuerza ilocucionaria de respaldo presente en el uso moral de proposiciones evaluativas, y se desligó de su función descriptiva. En este punto, por tanto, Ferrajoli presupone lo que intenta demostrar. Ahora bien, esto no significa que Ferrajoli no dé otras razones, ajenas por completo a lo que es su comprensión de ley de Hume y de la falacia naturalista, a favor de la exclusión propuesta. Pero presentar dichas razones bajo un manto de pretendida cientificidad neutral a la política debilita la discusión pública de un tema radicalmente político.

En un segundo momento, al tratar la pregunta de por qué castigar, Ferrajoli vuelve a servirse de la ley de Hume y de la falacia naturalista como supuestos límites en derecho penal. Así, afirma: "El vicio metodológico detectable en muchas de las respuestas examinadas hasta el momento a la pregunta '¿por qué castigar?' consiste en su confusión de la función o motivación con el fin, o del ser (de hecho o de derecho) con el deber ser (axiológico) de la pena, y en la consiguiente consideración de las explicaciones como justificaciones o viceversa" ${ }^{124}$. Para luego agregar:

"Llamaré 'ideologías' tanto a las doctrinas como a las teorías que incurren en la confusión entre modelos de justificación y esquemas de explicación. 'Ideología' ... es en efecto toda tesis o conjunto de tesis que confunde el 'deber ser' y el 'ser' (o las proposiciones normativas y las proposiciones asertivas), contraviniendo de este modo el principio meta-lógico conocido como 'ley de Hume', según el cual no se pueden derivar lógicamente conclusiones prescriptivas o morales de premisas descriptivas o fácticas, ni viceversa" ${ }^{125}$.

De estos fragmentos se extrae lo siguiente: del ser de la pena no se deriva el deber de la pena. Dicho de otro modo: de la proposición "X es una pena” no se extrae la proposición "X debe ser una pena". De conformidad con lo expuesto al inicio de este artículo surge evidente que la relación en la que estas proposiciones se encuentran entre sí es aquella relación en la que se encuentra una proposición cuyo contenido es cierto frente a una proposición cuyo contenido debe ser cierto. El tránsito de una a otra estaría prohibido por la ley de Hume, como bien lo anota Ferrajoli. Sin embargo, al igual que en el momento anterior, el punto crucial surge cuando Ferrajoli intenta derivar una consecuencia del uso de esta ley como límite en el tema de por qué castigar. Al respecto afirma lo siguiente:

"Podemos ahora trazar los requisitos metaéticos de un modelo de justificación de la pena capaz de escapar a los distintos tipos de falacia -naturalista y normativista- presentados hasta el momento, y por consiguiente de no verse degradado a ideología de legitimación apriorística ... El primer orden de requisitos se refiere a la valoración del fin penal justificador y de los medios penales a justificar ... Para que queden excluidas auto-justificaciones ideológicas del derecho penal y de las penas viciadas por la falacia naturalista, es necesario en primer lugar que el fin sea reconocido y compartido como un bien extra-jurídico, externo al derecho, y en segundo lugar que el medio jurídico sea reconocido como un mal, es decir, como un coste humano y social que precisamente por ello ha de ser justificado.

\footnotetext{
124 Ferrajoli (1995) p. 322.

125 Ferrajoli (1995) p. 323.
} 
Sólo así ... se evita la petición de principio que reduce la justificación a la descripción, el fin a las funciones o a los efectos jurídicos, el deber ser al ser del derecho" ${ }^{126}$.

La argumentación de Ferrajoli en este pasaje es más compleja. Lo primero que debe destacarse es que lo motiva la clara distinción entre los niveles de descripción y justificación, que para él son equivalentes, en este contexto, a ser y deber, respectivamente. La pretensión de justificar la pena, entonces, mediante el expediente de describir la pena estaría, así, prohibida por la ley de Hume. Su quebrantamiento aquí llevaría a lo que él denomina una teoría apriorística. Una vez establecido este punto, introduce dos elementos: el fin penal y el medio penal, ambos necesitados de justificación. Dado que, según él, debe distinguirse claramente entre descripción y justificación, debe entenderse entonces que Ferrajoli parte de las proposiciones, independientes entre sí, "X es el fin penal" y " $Z$ es el medio penal”. Éstas serían meras proposiciones descriptivas y estarían, por tanto, necesitadas de justificación. Ahora, como de una premisa descriptiva no se podría derivar una conclusión prescriptiva, según la ley de Hume, entonces de estas dos premisas no se podría, sin más, derivar las premisas "X debe ser el fin penal" y " $Z$ debe ser el medio penal".

Hasta aquí Ferrajoli se mueve en terreno seguro. Sin embargo, a renglón seguido agrega, como si se tratara de una consecuencia de la aplicación de la ley de Hume, que el fin penal debe ser un bien extra-jurídico y el medio penal un mal, so pena de reducir la justificación a la descripción. Es decir, Ferrajoli agrega las proposiciones "X es el fin penal y $\mathrm{X}$ tiene la característica A (bien extra-jurídico)" y " $\mathrm{Z}$ es el medio penal y $\mathrm{Z}$ tiene la característica B (mal)". No se ve, sin embargo, cómo estas definiciones de fin penal y medio penal pueden ser formuladas en cumplimiento de la ley de Hume, pues ésta se limitaría a afirmar que de la proposición "X es el fin penal" no se puede transitar a la proposición "X debe ser el fin penal". Salta a la vista, de otra parte, que la proposición agregada por Ferrajoli "X es el fin penal y X tiene la característica A" se encuentra frente a la proposición "X es el fin penal" en la misma relación en que se encuentra una proposición cuyo contenido está acompañado por una característica valorativa y otra cuyo contenido está acompañado por una característica descriptiva. Lo mismo cabe decir de la proposición agregada por Ferrajoli " $Z$ es el medio penal y $Z$ tiene la característica B" frente a " $Z$ es el medio penal". Ahora, la deducción de las primeras a partir de las segundas es algo que estaría prohibido por la falacia naturalista, como el mismo Ferrajoli acepta. No se entiende, entonces, por qué afirma llegar a estas definiciones como consecuencia del correcto entendimiento de la ley de Hume, la que antes bien quebranta, o de la falacia naturalista, en la que antes bien incurre.

Una vez más podemos esquematizar el proceder de Ferrajoli así: de la proposición "X es el fin penal" no se puede concluir, de conformidad con la falacia naturalista, "X es el fin penal y X tiene la caracterísitca A (u otra característica valorativa)". Sin embargo, afirma Ferrajoli, en aplicación de este límite se obtiene que "X es el fin penal y X tiene la característica A". Lo mismo cabe decir frente a sus reflexiones referidas al medio penal. Resulta evidente que aquí Ferrajoli quebranta su propio principio metodológico al presuponer, una vez más, lo que debería demostrar. Esta suposición, además, parte de un supuesto que no siempre tendría que ser cierto, a saber: que una descripción del fin o del medio penal

126 FerRajoli (1995) pp. 326 ss., bastardillas en el original. 
no estaría en lo absoluto relacionado con su justificación. Es cierto que hay razones para afirmar que esto no siempre tiene que ser así, y Ferrajoli apela a la historia del derecho para demostrarlo. Pero la posibilidad de asociar descripción y prescripción o, en términos más generales, ser y deber es el punto central para el cual Ferrajoli no tiene respuesta. Lo que no significa, una vez más, que sus suposiciones intuitivas y prerreflexivas no puedan ser correctas. Simplemente, no las somete a discusión pública.

Momentos similares a los dos ya reseñados se encuentran a lo largo de la obra de Ferrajoli. Así, al abordar el tema de la "legitimidad, validez, vigencia y efectividad" del derecho ("De acuerdo con la ley de Hume de la inderivabilidad entre juicios de hecho y juicios de valor -que es el primer significado, meta-lógico, que habíamos asociado a la tesis de la separación entre derecho y moral-, ni la validez ni la eficacia de una norma pueden ser deducidas de su vigencia"127), lo mismo que al abordar el tema de "la obligación jurídica y la obligación política de obedecer las leyes” (“... de la simple afirmación de una obligación jurídica no podemos derivar lógicamente, sin violar la 'ley de Hume’, la tesis de la existencia de una obligación moral de cumplirla" ${ }^{128}$ ). Dado que aquí también se repiten las críticas ya expuestas, no es necesario volver sobre ellas.

En su lugar ha de resaltarse que, a la luz de lo expuesto, la ley de Hume y la falacia naturalista, por sí mismas, no constituyen límite alguno de utilidad en derecho penal y, más bien, requieren de una teoría que provea una respuesta a la pregunta crucial, a saber: cuándo se puede pasar de una premisa descriptiva a una conclusión prescriptiva o, emparentado con lo anterior, cuándo se puede dar el tránsito de una premisa descriptiva a una valorativa. Esta comprensión nos ubica en el plano de la discusión con fundamento en razones. Y en este punto vuelvo a Atria: quizás sea mejor distinguir un escenario donde el discurso está sometido al tipo de razones que Atria, siguiendo a Detmold, denomina "extrínsecas", de otro escenario donde el discurso está sometido al tipo de razones que Atria, siguiendo a Detmold, denomina "intrínsecas" ${ }^{129}$. O, con otras palabras, distinguir, como en el modelo de estado legalista, entre legislación y adjudicación.

\section{BIBLIOGRAFÍA CITADA}

Anscombe, G.E.M. (1958a): "Modern Moral Philosophy”, Philosophy, vol. 33, No 124: pp. $1-19$.

Anscombe, G.E.M. (1958b): “On Brute Facts”, Analysis, vol. 18, No 3: pp. 69-72.

Atria, Fernando (2016): La forma del derecho (Madrid, Barcelona, Buenos Aires y San Pablo, Marcial Pons).

Austin, J.L. (1962): How to do things with Words (Londres, Oxford University Press).

Beckermann, Ansgar (2008): Analytische Einführung in die Philosophie des Geistes (Berlín, Walter de Gruyter, tercera edición).

\footnotetext{
127 Ferrajoli (1995) p. 359.

128 Ferrajoli (1995) p. 921.

129 Véase Atria (2016) p. 80, pie de página 3.
} 
Birnbacher, Dieter (2007): Analytische Einführung in die Ethik (Berlín, Walter de Gruyter, segunda edición).

Brandom, Robert B. (1994): Making It Explicit (Cambridge y Londres, Harvard University Press).

Brandom, Robert B. (2000): Articulating Reasons (Cambridge y Londres, Harvard University Press).

Broad, C.D. (1930): Five Types of Ethical Theory (Londres, Routledge \& Kegan Paul).

Cragg, A.W. (1976): "Functional Words, Facts and Values", Canadian Journal of Philosophy, vol. 6, No 1: pp. 77-94.

Davidson, Donald (2001a): Inquiries into Truth and Interpretation (Oxford, Oxford University Press, segunda edición).

Davidson, Donald (2001b): Subjective, Intersubjective, Objective (Oxford, Oxford University Press).

Davidson, Donald (2004): Problems of Rationality (Oxford, Oxford University Press).

Ferrajoli, Luigi (1995): Derecho y Razón. Teoría del Garantismo Penal (trad. Perfecto Andrés Ibáñez, Alfonso Ruíz Miguel, Juan Carlos Bayón Mohino, Juan Terradillos Basoco, Rocio Cantarero Bandrés, Madrid, Editorial Trotta).

Ferrajoli, Luigi (2001): "Pasado y futuro del Estado de derecho", Revista internacional de filosofía política, vol. 17: pp. 31-45.

FLEW, Antony (1964): “On not Deriving 'Ought' from 'Is”, Analysis, vol. 25, No 2: 25-32.

Geach, P.T. (1956): “Good and Evil”, Analysis, vol. 17, No 2: pp. 33-42.

Goodman, Nelson (1983): Fact, Fiction, and Forecast (Cambridge y Londres, Harvard University Press, cuarta edición).

Grundmann, Thomas (2008): Analytische Einführung in die Erkenntnistheorie (Berlín, Walter de Gruyter).

Habermas, Jürgen (1983): Moralbewußtsein und kommunikatives Handeln (Fráncfort del Meno, Suhrkamp).

HaberMas, Jürgen (1992): Faktizität und Geltung (Fráncfort del Meno, Suhrkamp).

Hare, R.M. (1952): The Language of Morals (Londres, Oxford University Press).

Hare, R.M. (1954-1955): "Universalisability", Proceedings of the Aristotelian Society, vol. 55: 295-312.

Hare, R.M. (1957): “Geach: Good and Evil”, Analysis, vol. 17, No 5: pp. 103-111.

Hume, David (1949): A Treatise of Human Nature (Londres, Oxford University Press, año original de edición: 1739).

Kant, Immanuel (1911a): "Kritik der reinen Vernunft", Kants gesammelte Schriften. Akademie Ausgabe, Tomo III (Berlín, Georg Reimer, año original de edición: 1787).

KanT, Immanuel (1911b): “Grundlegung zur Metaphysik der Sitten”, Kants gesammelte Schriften. Akademie Ausgabe, Tomo IV (Berlín, Georg Reimer, año original de edición: 1785).

KindHÄUSER, Urs (1989): Gefährdung als Straftat (Fráncfort del Meno, Vittorio Klostermann). MacIntyre, A.C. (1959): "Hume on 'is' and 'ought", The Philosophical Review, vol. 68, No 4: pp. 451-468.

MACKIE, J.L. (1977): Ethics. Inventing right and wrong (Londres, Penguin Books). 
Mañalich, Juan Pablo (2009): Nötigung und Verantwortung (Baden-Baden, Nomos).

Mañalich, Juan Pablo (2018): "El principialismo político-criminal como fetiche”, Revista de Estudios de la Justicia, No 29: pp. 59-71.

Moore, G.E. (1903): Principia Ethica (Londres, Cambridge University Press).

Moore, M.S. (2002): "Legal Reality: A Naturalist Approach to Legal Ontology", Law and Philosophy, vol. 21, No 6: pp. 619-705.

Neumann, Ulfrid (1991): "Moralphilosophie und Strafrechtsdogmatik", Archiv für Rechtsund Sozialphilosophie, Beiheft 44: pp. 248-259.

Neumann, Ulfrid (1994): "Die Moral des Rechts", Jahrbuch für Recht und Ethik, vol. 2: pp. 81-94.

Putnam, Hilary (2002): The Collapse of the Fact/Value Dichotomy (Cambridge y Londres, Harvard University Press).

Putnam, Hilary (2004): Ethics without Ontology (Cambridge y Londres, Harvard University Press).

Quine, Willard Van Orman (1960): Word and Object (Nueva York y Londres, The Technology Press of the Massachusetts Institute of Technology y John Wiley \& Sons).

Searle, John R. (1964): "How to Derive 'Ought' From 'Is', The Philosophical Review, vol. 73, No 1: pp. 43-58.

Searle, John R. (1969): Speech Acts (Londres, Cambridge University Press).

Silva SÁnchez, Jesús-María (2018): Malum passionis. Mitigar el dolor del derecho penal (Barcelona, Atelier).

Strawson, P.F. (1952): Introduction to Logical Theory (Londres, Methuen \& Co Ltd.).

SuÁrez López, Carlos Alberto (2010): "La falacia naturalista y la falacia normativista en la ciencia del derecho penal: dos errores metodológicos y una propuesta para su superación”, Derecho penal contemporáneo, vol. 33: pp. 31-48.

Ross, W.D. (1930): The Right and the Good (Londres, Oxford University Press).

\section{JURISPRUDENCIA CITADA}

Corte Constitucional. Sentencia del 5 de junio de 1992. Magistrado Ponente: Ciro Angarita Barón. Sentencia T-406.

Corte Constitucional. Sentencia del 1 de marzo de 1995. Magistrado Ponente: Carlos Gaviria Díaz. Sentencia C-83.

Corte Constitucional. Sentencia del 5 de junio de 2019. Magistrado Ponente: Cristina Pardo Schlesinger. Sentencia C-248, Jurisprudencia \& Doctrina No 575 (2019), pp. 2006-2036.

Corte Suprema de Justicia. Sentencia del 27 de febrero de 2013. Magistrado Ponente: José Leonidas Bustos Ramírez. Sentencia 33254. 